\title{
Prevalence of prehypertension and its relationship to risk factors for cardiovascular disease in Jamaica: Analysis from a cross-sectional
} survey

\author{
Trevor S Ferguson ${ }^{1}$, Novie OM Younger ${ }^{1}$, Marshall K Tulloch-Reid ${ }^{1}$, \\ Marilyn B Lawrence Wright ${ }^{1}$, Elizabeth M Ward ${ }^{2}$, Deanna E Ashley ${ }^{2}$ and \\ Rainford J Wilks*1
}

Address: ${ }^{1}$ Tropical Medicine Research Institute, University of the West Indies, Mona, Kingston 7, Jamaica and ${ }^{2}$ Ministry of Health, Jamaica

Email: Trevor S Ferguson - trevor.ferguson02@uwimona.edu.jm; Novie OM Younger - novie.younger@uwimona.edu.jm; Marshall K TullochReid - marshall.tullochreid@uwimona.edu.jm; Marilyn B Lawrence Wright - marilyn.lawrencewright@uwimona.edu.jm;

Elizabeth M Ward - warde@moh.gov.jm; Deanna E Ashley - deca@cwjamaica.com; Rainford J Wilks* - rainfordw@cwjamaica.com

* Corresponding author

Published: 28 August 2008

BMC Cardiovascular Disorders 2008, 8:20 doi:10.1/86/147/-226I-8-20

This article is available from: http://www.biomedcentral.com/|47|-226I/8/20

(c) 2008 Ferguson et al; licensee BioMed Central Ltd.

This is an Open Access article distributed under the terms of the Creative Commons Attribution License (http://creativecommons.org/licenses/by/2.0), which permits unrestricted use, distribution, and reproduction in any medium, provided the original work is properly cited.
Received: 17 January 2008

Accepted: 28 August 2008

\begin{abstract}
Background: Recent studies have documented an increased risk of cardiovascular disease (CVD) in persons with systolic blood pressures of $120-139 \mathrm{mmHg}$ and/or diastolic blood pressures of $80-89 \mathrm{mmHg}$, classified as prehypertension in the Seventh Report of the Joint National Committee on Prevention, Detection, Evaluation, and Treatment of High Blood Pressure. In this paper we estimate the prevalence of prehypertension in Jamaica and evaluate the relationship between prehypertension and other risk factors for CVD.
\end{abstract}

Methods: The study used data from participants in the Jamaica Lifestyle Survey conducted from 2000-200I. A sample of 2012 persons, 15-74 years old, completed an interviewer administered questionnaire and had anthropometric and blood pressure measurements performed by trained observers using standardized procedures. Fasting glucose and total cholesterol were measured using a capillary blood sample. Analysis yielded crude, and sex-specific prevalence estimates for prehypertension and other CVD risk factors. Odds ratios for associations of prehypertension with CVD risk factors were obtained using logistic regression.

Results: The prevalence of prehypertension among Jamaicans was 30\% (95\% confidence interval [Cl] 27\%-33\%). Prehypertension was more common in males, 35\% (Cl $31 \%-39 \%)$, than females, $25 \%$ (Cl 22\%-28\%). Almost $46 \%$ of participants were overweight; $19.7 \%$ were obese; $14.6 \%$ had hypercholesterolemia; $7.2 \%$ had diabetes mellitus and $17.8 \%$ smoked cigarettes. With the exception of cigarette smoking and low physical activity, all the CVD risk factors had significantly higher prevalence in the prehypertensive and hypertensive groups ( $\mathrm{p}$ for trend $<0.00 \mathrm{I}$ ) compared to the normotensive group. Odds of obesity, overweight, high cholesterol and increased waist circumference were significantly higher among younger prehypertensive participants (I5-44 yearsold) when compared to normotensive young participants, but not among those 45-74 years-old. Among men, being prehypertensive increased the odds of having $>/=3$ CVD risk factors versus no risk factors almost three-fold (odds ratio [OR] 2.8 [Cl I.I-7.2]) while among women the odds of $>/=3$ CVD risk factors was increased two-fold (OR 2.0 [Cl I.3-3.8]) 
Conclusion: Prehypertension occurs in 30\% of Jamaicans and is associated with increased prevalence of other CVD risk factors. Health-care providers should recognize the increased CVD risk of prehypertension and should seek to identify and treat modifiable risk factors in these persons.

\section{Background}

The relationship between blood pressure and cardiovascular mortality is thought to be linear with no definite lower threshold that identifies potential danger or cessation of benefit $[1,2]$. Recent studies have documented an increase in the risk of cardiovascular disease and a high rate of progression to hypertension in persons with systolic blood pressures between 120 to $139 \mathrm{mmHg}$ and/or diastolic blood pressures between 80 and $89 \mathrm{mmHg}$ [2-4]. In addition, there have been reported associations between borderline hypertension (systolic 130-140 mm $\mathrm{Hg}$ or diastolic 85-89 $\mathrm{mm} \mathrm{Hg}$ ) and high normal blood pressure (systolic 130-139 mmHg or diastolic 85-89 $\mathrm{mmHg}$ ) with several risk markers for cardiovascular events, such as increased carotid intima-media thickness, left ventricular hypertrophy and microalbuminuria [5-8]. Based on the current evidence, the Seventh Report of the Joint National Committee on Prevention, Detection, Evaluation, and Treatment of High Blood Pressure (JNC 7) [9] recommended a new classification for blood pressure in which normal blood pressure is defined as systolic blood pressure $<120 \mathrm{mmHg}$ and diastolic blood pressure of < $80 \mathrm{mmHg}$, while persons with systolic blood pressure of 120 to $139 \mathrm{mmHg}$ and/or diastolic blood pressure of 80 to $89 \mathrm{mmHg}$ are classified as having prehypertension. This new classification places a large number of persons previously considered as normal in this higher risk category and emphasizes the need for monitoring and possible intervention in persons with blood pressures between the range of normal and hypertensive.

Since the publication of JNC 7 a number of studies have reported associations between prehypertension and other risk factors for cardiovascular disease. These include obesity, high total cholesterol, diabetes mellitus [10], elevated C-reactive protein $[11,12]$ and left ventricular hypertrophy [13]. One study reported an association between prehypertension and coronary atherosclerosis in persons undergoing coronary angiograms [14]. Little is known about the association between these risk factors and prehypertension in Jamaica.

To date, there are only a few reports of national prevalence estimates for prehypertension, with estimates ranging from $30 \%$ to $48.9 \%$ [15-19]. In most of theses studies, prehypertension was more common than hypertension. The prevalence of prehypertension in Jamaica is not known. However, hypertension is known to be common in Jamaica and other developing countries of the Caribbean region. Population-based studies have shown a prevalence of hypertension of approximately $20 \%$ in persons 15-74 years old in Jamaica [20].

The aim of this study was to estimate the prevalence of prehypertension from a population-based study - The Jamaica Lifestyle Survey [21]. In order to assess overall cardiovascular risk, we also examined the association between prehypertension and some known risk factors for cardiovascular disease, specifically diabetes mellitus, overweight or obesity, high-risk waist circumference and hypercholesterolaemia.

\section{Methods}

The Jamaica Healthy Lifestyle Survey 2000-2001 studied 2012 persons between the ages of 15 and 74 years in order to estimate the prevalence of hypertension, diabetes and obesity in Jamaica. The details of the study design and conduct have been previously published [21]. Participants were asked to complete an interviewer-administered questionnaire and had anthropometric and blood pressure measurements performed by trained observers using standardized procedures. Fasting blood glucose and total cholesterol were measured using a capillary blood sample.

Blood pressure was measured from the right arm of the seated participant after five minutes rest and was recorded to the nearest $2 \mathrm{mmHg}$ using 1 st and 5th Korotkoff sounds. Three blood pressure measurements were taken and the mean of the last two measurements was used in the analysis. Height was measured with a portable stadiometer and recorded to the closest $0.1 \mathrm{~cm}$. Waist circumference and hip circumference were measured with a nonstretchable tape measure to the nearest $0.1 \mathrm{~cm}$. Weight was measured with an electronic digital scale to the nearest $0.1 \mathrm{~kg}$. Measurements were conducted by trained personnel and all instruments were calibrated once weekly. Fasting blood glucose and total cholesterol were measured after a 10 hour overnight fast using a capillary blood sample analyzed with the Accutrend GCT Roche Diagnostics GmbH instrument.

The protocol for the study was reviewed and approved by Ethics Committees in the Faculty of Medical Sciences of the University of the West Indies, Mona and in the Ministry of Health, Jamaica. 


\section{Definitions}

Prehypertension was defined according to JNC 7 criteria as having either a systolic blood pressure of 120 to139 $\mathrm{mmHg}$ and/or diastolic blood pressure of 80 to $89 \mathrm{mmHg}$ in persons who were not on treatment for hypertension. Hypertension was also defined according to JNC 7 criteria as having an untreated systolic blood pressure (BP) of greater than or equal to $140 \mathrm{mmHg}$ or diastolic BP greater than or equal to $90 \mathrm{mmHg}$ or being on medication for hypertension. Normal blood pressure was defined as having both a systolic BP of $<120 \mathrm{mmHg}$ and a diastolic BP of $<80 \mathrm{mmHg}$ in the absence of antihypertensive medication. Diabetes mellitus was defined as having a fasting glucose of greater than or equal to $6.1 \mathrm{mmol} / \mathrm{L}$ or being on treatment for diabetes [22]. Body mass index (BMI) was calculated as weight in kilograms divided by the square of the height in metres. Overweight was defined as a BMI greater than or equal to $25 \mathrm{~kg} / \mathrm{m}^{2}$, while obesity was defined as BMI greater than or equal $30 \mathrm{~kg} / \mathrm{m}^{2}$ [23]. Increased (high-risk) waist circumference was defined as recommended by Lean et al. [24], as greater than $94 \mathrm{~cm}$ in men and greater than $80 \mathrm{~cm}$ in women. Increased waist to hip ratio was defined as greater than or equal to 0.95 for males and greater than or equal to 0.80 for females. Hypercholesterolaemia was defined as fasting total serum cholesterol of greater than or equal to $5.2 \mathrm{mmol} / \mathrm{L}(200$ $\mathrm{mg} / \mathrm{dL}$ ). Cigarette smoking was defined as smoking one or more cigarettes per day.

Physical activity status defined using information obtained from the questionnaire. Low activity persons was defined as infrequent ( $<3$ times per week) involvement in energy expenditure at either work, traveling to work or leisure-time activities.

\section{Statistical Methods}

Data analysis was carried out using Stata Version 9 [25]. Analysis was restricted to 1972 participants with blood pressure data. Individual weights were created to correct for discrepancies between the age-sex distribution of the sample and that of the Jamaican population of 15-74 year-olds [21]. Standard error estimates for population prevalence were adjusted to account for the multistage sampling design used in this study. The chi-squared statistic corrected for survey design determined evidence of statistically significant association between cardiovascular risk factors and blood pressure categories. The chi-squared test for trend identified statistically significant trends in prevalence of cardiovascular risk factors across ordinal blood pressure categories. Multivariate logistic regression analysis provided estimates of the odds of prehypertensive participants having given CVD risk factors as well as various clusters of risk factors, namely, central obesity (having a high-risk waist circumference), smoking cigarettes, having diabetes mellitus, having high cholesterol or being older than forty five years. Separate models were created for each cardiovascular risk factor. Each model estimated the relative increase in the odds of having the respective risk factor for prehypertensive persons compared with normotensive persons. Odds ratios from models with hypercholesterolaemia or diabetes as outcome variable were adjusted for age, sex and overweight status. Odds ratios from models with measures of obesity as the outcome variable were adjusted for age, sex, diabetes and hypercholesterolaemia. We report age-group specific estimates of these odds ratios from models that gave statistically significant evidence of an interaction of age with prehypertension.

To examine the clustering of risk factors for cardiovascular disease, we estimated the proportion of participants within blood pressure categories having one, two or three or more of the five aforementioned additional risk factors. We then used logistic regression models to calculate sexspecific, age adjusted odds ratios for having one, two, or three or more additional risk factors among prehypertensive participants compared to those with normal blood pressure.

\section{Results}

Of the 1972 participants included in the analyses 661 (33.5\%) were males and 1311 (66.5\%) were females. The mean age was $36.3 \pm 0.45$ years with no sex difference. Selected characteristics of participants in the survey grouped according to blood pressure categories are shown in Table 1. With the exception of height, the mean values for the characteristics presented were significantly higher ( $\mathrm{p}<0.001$ ) among the prehypertensive and hypertensive groups compared to those with normal blood pressure. There was also a statistically significant trend ( $\mathrm{p}<0.001)$ for higher means of all characteristics, except height, going from normal blood pressure to hypertension. Comparison of the mean values for the other variables of interest between those who were excluded because of a missing value and those included, revealed no differences except for age, where those with any missing values were younger than those with no missing values (37.7 vs. $41.3, \mathrm{p}=$ $0.003)$.

The overall prevalence of prehypertension among Jamaicans 15-74 years old was found to be 30\% (95\% confidence interval [CI] 27\%-33\%). Prehypertension was more common in men than women, 35\% (CI 31\%-39\%) and $25 \%$ (CI 22\%-28\%) respectively ( $\mathrm{p}<0.001$ for malefemale difference in proportion). Age and sex specific prevalence estimates are shown Figure 1. Prehypertension was more common in men than women at all ages except in the 65-74 year old age group. Among men, prehypertension prevalence ranged between 35-39\% for the 15-64 year-old age groups then fell to $20 \%$ among those 
Table I: Means and standard error for selected characteristics of participants in the Jamaica Lifestyle Survey 2000-200 I within and across blood pressure categories.

\begin{tabular}{|c|c|c|c|c|c|c|}
\hline & & $\begin{array}{c}\text { Total } \\
N=1972\end{array}$ & $\begin{array}{c}\text { Normotensive* } \\
\quad N=875\end{array}$ & $\begin{array}{l}\text { Prehypertensive } \\
\qquad N=555\end{array}$ & $\begin{array}{c}\text { Hypertensive } \\
N=542\end{array}$ & $\mathrm{p}$-value for association $* *$ \\
\hline Characteristics & $N$ & Mean $\pm S E^{\#}$ & Mean \pm SE & Mean \pm SE & Mean \pm SE & \\
\hline Age (years) & 1953 & $36.3 \pm 0.45$ & $30.3 \pm 0.44$ & $36.6 \pm 0.73$ & $50.2 \pm 0.83$ & $<0.001$ \\
\hline Weight (kg) & 1939 & $71.5 \pm 0.47$ & $67.5 \pm 0.55$ & $74.0 \pm 0.75$ & $77.5 \pm 1.01$ & $<0.001$ \\
\hline Height $(\mathrm{cm})$ & 1936 & $167.1 \pm 0.33$ & $166.6 \pm 0.39$ & $168.6 \pm 0.56$ & $166.2 \pm 0.54$ & 0.002 \\
\hline Waist circumference $(\mathrm{cm})$ & 1944 & $82.3 \pm 0.41$ & $77.9 \pm 0.48$ & $84.1 \pm 0.64$ & $90.3 \pm 0.86$ & $<0.001$ \\
\hline Hip Circumference (cm) & 1935 & $99.7 \pm 0.46$ & $97.1 \pm 0.53$ & $101.3 \pm 0.62$ & $103.8 \pm 0.73$ & $<0.001$ \\
\hline Waist to Hip Ratio & 1932 & $0.82 \pm 0.003$ & $0.82 \pm 0.003$ & $0.83 \pm 0.003$ & $0.86 \pm 0.005$ & $<0.001$ \\
\hline Body mass index $\left(\mathrm{kg} / \mathrm{m}^{2}\right)$ & 1930 & $25.7 \pm 0.18$ & $24.4 \pm 0.22$ & $26.1 \pm 0.28$ & $28.1 \pm 0.38$ & $<0.001$ \\
\hline Cholesterol level (mmol/L) & 1848 & $4.5 \pm 0.02$ & $4.3 \pm 0.2$ & $4.5 \pm 0.46$ & $4.8 \pm 0.06$ & $<0.001$ \\
\hline Fasting Glucose (mmol/L) & 1881 & $4.3 \pm 0.05$ & $4.0 \pm 0.04$ & $4.21 \pm 0.07$ & $5.0 \pm 0.12$ & $<0.001$ \\
\hline
\end{tabular}

* Normotensive: blood pressure (BP) < I20/80 mmHg; Prehypertensive: BP = I20-139/80-89 mmHg and not on anti-hypertensive medication; Hypertensive: BP $\geq 140 / 90$ or on anti-hypertensive medication

** Apart from height all characteristics showed a statistically significant increasing trend $(\mathrm{P}<0.00 \mathrm{I})$ going from normotensive to hypertensive $\#$ SE = Standard error

aged 65-74 years old (p for trend 0.04). Among women however, prehypertension prevalence was low at $18 \%$ among the youngest age group, and increased with age up to the 45-54 year-old age group, where the prevalence was $31 \%$, after which there was a decline in the older age groups, 23\% and 22\% in the 55-64 year-old and 65-74 year-old age groups respectively (the test for trend was not significant).

Table 2 shows the crude and sex-specific prevalence of cardiovascular risk factors among participants in the study. Overall there was high prevalence of obesity in the study population. Almost $46 \%$ of participants were overweight $\left(\geq 25 \mathrm{~kg} / \mathrm{m}^{2}\right) ; 19.7 \%$ were obese $\left(\geq 30 \mathrm{~kg} / \mathrm{m}^{2}\right) ; 30.5 \%$ had increased waist/hip ratio while $36 \%$ had increased waist circumference. The prevalence low physical activity levels was estimated at 36.3\%. Prevalence estimates were lower for other CVD risk factors: $14.6 \%$ for hypercholesterolemia, $7.2 \%$ for diabetes mellitus and $17.8 \%$ for cigarette smoking. There were marked sex differences in the prevalence of CVD risk factors except for diabetes mellitus. For measures of obesity, prevalence was two to nine times higher among women compared to men $(\mathrm{p}<0.001$ for all measures).

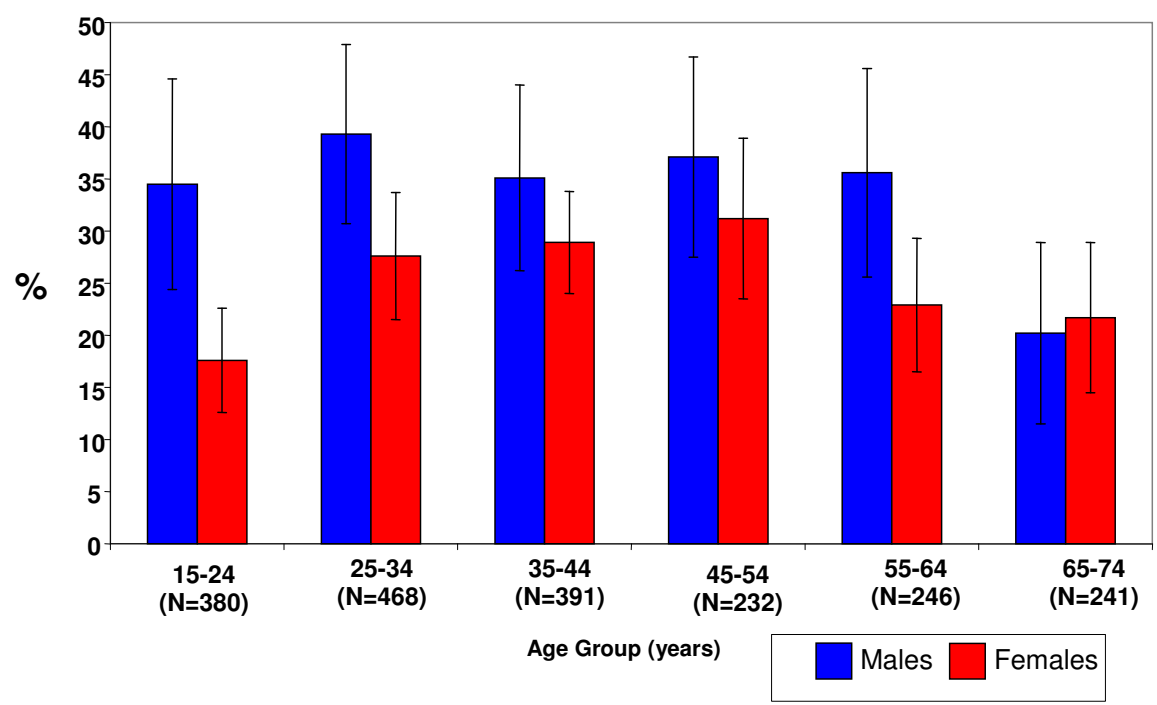

\section{Figure I}

Age-group and sex specific prevalence of prehypertension (with $95 \%$ confidence intervals shown as error bars) in the Jamaica Lifestyle Survey 2000-200I. 
Table 2: Crude and sex-specific prevalence of cardiovascular disease risk factors in the Jamaica Lifestyle Survey 2000-200 I.

\begin{tabular}{|c|c|c|c|}
\hline Characteristics & $\begin{array}{c}\text { Male } \\
(N=661)\end{array}$ & $\begin{array}{c}\text { Female } \\
(N=|3| 1)\end{array}$ & $\begin{array}{c}\text { Total } \\
(\mathrm{N}=1972)\end{array}$ \\
\hline & $\%(95 \% \mathrm{Cl})$ & $\%(95 \% \mathrm{Cl})$ & $\%(95 \% \mathrm{Cl})$ \\
\hline Obesity** (BMI $\geq 30$ kg/m²) & $9.0(6.8-11.3)$ & $30.0(26.8-33.2)$ & $19.7(17.4-22.0)$ \\
\hline Overweight** (BMI $\left.\geq 25 \mathrm{~kg} / \mathrm{m}^{2}\right)$ & $30.2(25.7-34.6)$ & $60.7(57.4-64.0)$ & $45.7(42.6-48.9)$ \\
\hline Increased Waist Circumference ${ }^{* *}$ & $14.6(11.6-17.6)$ & $56.7(53.2-60.2)$ & $36.0(33.0-39.0)$ \\
\hline Increased Waist/Hip ratio** & $6.1(4.0-8.1)$ & $54.4(50.6-58.2)$ & $30.5(27.9-33.2)$ \\
\hline Hypercholesterolaemia* & $11.6(8.8-14.5)$ & $17.4(15.1-19.8)$ & $14.6(12.7-16.5)$ \\
\hline Diabetes Mellitus & $6.3(4.3-8.3)$ & $8.0(6.6-9.4)$ & $7.2(6.0-8.3)$ \\
\hline 'Cigarette Smoking** & $28.3(24.1-32.5)$ & $7.3(5.6-8.9)$ & $17.6(15.2-20.1)$ \\
\hline Low Physical activity** & $21.3(17.3-25.4)$ & $50.9(46.8-54.9)$ & $36.3(33.0-39.7)$ \\
\hline
\end{tabular}

I Currently smokes cigarettes regardless of quantity per day.

$* \mathrm{P}<0.01$ (male - female difference in proportions)

$* * \mathrm{P}<0.001$ (male - female difference in proportions)

Table 3 shows the sex-specific prevalence of CVD risk factors and risk factor clusters by blood pressure categories with assessment for trends moving from normal to high blood pressure. With the exception of cigarette smoking and low physical activity levels all the CVD risk factors studied had significantly higher prevalence in the prehypertensive and hypertensive groups compared to the normotensive group among both men and women. There were also statistically significant trends $(p<0.001)$ for higher prevalence going from normal to high blood pressure. Low physical activity was also associated with blood pressure among men with higher prevalence among those with prehypertension or hypertension. Among women however, the prevalence of low physical activity was high in all blood pressure categories. For cigarette smoking, persons with hypertension had lower prevalence of cigarette smoking compared to those with normal blood pressure or prehypertension among both men and women.

The proportion of persons with clustering of CVD risk factors are also shown in Table 3. They are grouped as "no additional risk factor", "one additional risk factor", "two additional risk factors" and three or more additional risk factors"; and reported as sex-specific estimates by blood pressure category. Compared with normotensive men, those with prehypertension were more likely to have two additional risk factors (19.6\% among prehypertensive vs. $11.0 \%$ among normotensive), or three or more additional risk factors (6.8\% among prehypertensive vs. $1.8 \%$ among normotensive persons). Similarly, among women, a higher proportion of those with prehypertension had one, two and three or more risk factors compared to those with normal blood pressure. Almost $41 \%$ of prehypertensive women had one additional risk factor, $25.8 \%$ had two additional risk factors, and $10.6 \%$ had three or more risk factors, compared to $33.6 \%, 13.8 \%$ and $4.2 \%$ for the respective groups with normal blood pressure.
In order to estimate the relative risk for the presence of CVD risk factors among person with prehypertension compared to those with normal blood pressure, odds ratios were obtained using logistic regression models with adjustments for age and sex and other CVD risk factors as stated above. These odds ratios are shown in Table 4 . There was significant effect modification with age and therefore age-group specific odds ratios were calculated. There was no significant association for the odds of diabetes mellitus among prehypertensive persons in any age group. Odds of obesity, overweight, high cholesterol and increased waist circumference tended to be significantly higher among young persons (15-44 year olds) with prehypertension compared to young persons with normal blood pressure. The odds ratio for increased waist/hip ratio was only significant among younger prehypertensive persons in the age group 15-24 years. In the older age groups (45 year olds and older), while the odds of the CVD risk factors were often higher among those with prehypertension the association was not significant except for increased waist/hip ratio in the 45-54 year-old age group.

We also estimated the age-adjusted odds ratio for relative increase in odds for one, two, and three or more risk factors compared to having no risk factors for male and female prehypertensive participants compared to normotensive participants. Among men, being prehypertensive is associated with an almost three-fold (OR 2.8 [CI $1.1-7.2]$ ) increase in the odds of having three or more risk factors, while there is no apparent increased odds associated with two (OR $1.4[0.7-2.9]$ ) or one (OR 0.8 [0.5-1.4]) CVD risk factors. Among women, being prehypertensive is associated with increased odds at all levels of other CVD risk factors, with an approximately two-fold increase in the odds at each level of risk. The odds ratio for having three or more risk factors was 2.0 (95\%CI 1.3-3.0) 
Table 3: Prevalence of individual cardiovascular disease risk factors and risk factor clusters by sex and blood pressure categories in the Jamaica Lifestyle Survey 2000-200I.

\begin{tabular}{|c|c|c|c|c|c|c|c|c|}
\hline \multicolumn{9}{|c|}{ Individual Cardiovascular Disease Risk Factor } \\
\hline & \multicolumn{4}{|c|}{ Male } & \multicolumn{4}{|c|}{ Female } \\
\hline & $\begin{array}{c}\text { Normal BP } \\
\% \\
(95 \% \mathrm{Cl})\end{array}$ & $\begin{array}{c}\text { Pre-HTN } \\
\% \\
(95 \% \mathrm{Cl})\end{array}$ & $\begin{array}{c}\mathrm{HTN} \\
\% \\
(95 \% \mathrm{Cl})\end{array}$ & $\begin{array}{l}\text { P-value } \\
\text { (trend) }\end{array}$ & $\begin{array}{c}\text { Normal BP } \\
\% \\
(95 \% \mathrm{Cl})\end{array}$ & $\begin{array}{c}\text { Pre-HTN } \\
\% \\
(95 \% \mathrm{Cl})\end{array}$ & $\begin{array}{c}\mathrm{HTN} \\
\% \\
(95 \% \mathrm{Cl})\end{array}$ & $\begin{array}{l}\text { P-value } \\
\text { (trend) }\end{array}$ \\
\hline Obesity & $\begin{array}{c}4.8 \\
(2.0-7.5)\end{array}$ & $\begin{array}{c}8.6 \\
(4.9-12.4)\end{array}$ & $\begin{array}{c}19.5 \\
(11.8-27.1)\end{array}$ & $<0.001$ & $\begin{array}{c}19.7 \\
(16.6-22.8)\end{array}$ & $\begin{array}{c}39.0 \\
(32.7-45.2)\end{array}$ & $\begin{array}{c}45.4 \\
(39.6-51.3)\end{array}$ & $<0.001$ \\
\hline Overweight & $\begin{array}{c}19.2 \\
(14.4-24.0)\end{array}$ & $\begin{array}{c}31.2 \\
(24.9-37.5)\end{array}$ & $\begin{array}{c}53.3 \\
(43.3-63.4)\end{array}$ & $<0.001$ & $\begin{array}{c}48.4 \\
(44.1-52.8)\end{array}$ & $\begin{array}{c}71.3 \\
(65.8-76.9)\end{array}$ & $\begin{array}{c}79.1 \\
(75.2-83.3)\end{array}$ & $<0.001$ \\
\hline $\begin{array}{r}\text { Increased } \\
\text { Waist } \\
\text { Circumference }\end{array}$ & $\begin{array}{c}6.3 \\
(3.2-9.4)\end{array}$ & $\begin{array}{c}13.7 \\
(8.7-18.6)\end{array}$ & $\begin{array}{c}34.6 \\
(26.3-43.0)\end{array}$ & $<0.001$ & $\begin{array}{c}42.4 \\
(37.9-46.8)\end{array}$ & $\begin{array}{c}66.9 \\
(60.8-72.9)\end{array}$ & $\begin{array}{c}81.1 \\
(77.1-85.1)\end{array}$ & $<0.001$ \\
\hline $\begin{array}{r}\text { Increased } \\
\text { Waist } / \text { Hip } \\
\text { ratio }\end{array}$ & $\begin{array}{c}2.6 \\
(0.4-4.9)\end{array}$ & $\begin{array}{c}4.7 \\
(2.0-7.6)\end{array}$ & $\begin{array}{c}16.2 \\
(9.4-23.1)\end{array}$ & $<0.001$ & $\begin{array}{c}42.1 \\
(37.2-47.0)\end{array}$ & $\begin{array}{c}60.4 \\
(54.6-66.2)\end{array}$ & $\begin{array}{c}78.1 \\
(72.6-83.5)\end{array}$ & $<0.001$ \\
\hline Hypercholesterolaemia & $\begin{array}{c}5.6 \\
(2.6-8.7)\end{array}$ & $\begin{array}{c}13.7 \\
(8.6-18.6)\end{array}$ & $\begin{array}{c}21.4 \\
(14.3-28.4)\end{array}$ & $<0.001$ & $\begin{array}{c}11.4 \\
(8.9-13.9)\end{array}$ & $\begin{array}{c}21.5 \\
(16.5-26.5)\end{array}$ & $\begin{array}{c}27.7 \\
(22.7-32.6)\end{array}$ & $<0.001$ \\
\hline $\begin{array}{c}\text { Diabetes } \\
\text { Mellitus }\end{array}$ & $\begin{array}{c}2.2 \\
(0.6-3.8)\end{array}$ & $\begin{array}{c}4.3 \\
(1.9-6.6)\end{array}$ & $\begin{array}{c}19.0 \\
(12.1-25.9)\end{array}$ & $<0.001$ & $\begin{array}{c}2.4 \\
(1.3-3.5)\end{array}$ & $\begin{array}{c}7.2 \\
(4.8-9.5)\end{array}$ & $\begin{array}{c}22.4 \\
(17.5-27.2)\end{array}$ & $<0.001$ \\
\hline $\begin{array}{r}\text { 'Cigarette } \\
\text { Smoking }\end{array}$ & $\begin{array}{c}31.7 \\
(24.6-38.8)\end{array}$ & $\begin{array}{c}28.8 \\
(21.6-35.9)\end{array}$ & $\begin{array}{c}19.8 \\
(14.2-25.4)\end{array}$ & 0.004 & $\begin{array}{c}8.0 \\
(5.7-10.3)\end{array}$ & $\begin{array}{c}6.8 \\
(3.7-10.0)\end{array}$ & $\begin{array}{c}5.9 \\
(3.2-8.5)\end{array}$ & 0.033 \\
\hline $\begin{array}{r}\text { Low Physical } \\
\text { Activity }\end{array}$ & $\begin{array}{c}18.7 \\
(13.1-24.3)\end{array}$ & $\begin{array}{c}20.8 \\
(14.1-27.4)\end{array}$ & $\begin{array}{c}28.3 \\
(20.4-36.2)\end{array}$ & 0.007 & $\begin{array}{c}52.0 \\
(47.2-56.9)\end{array}$ & $\begin{array}{c}46.2 \\
(39.8-52.7)\end{array}$ & $\begin{array}{c}53.4 \\
(46.2-60.6)\end{array}$ & 0.181 \\
\hline
\end{tabular}

Risk Factor Clustering ${ }^{2}$

\begin{tabular}{|c|c|c|c|c|c|c|c|c|}
\hline & \multicolumn{4}{|c|}{ Male } & \multicolumn{4}{|c|}{ Female } \\
\hline & $\begin{array}{c}\text { Normal BP } \\
\% \\
(95 \% \mathrm{Cl})\end{array}$ & $\begin{array}{c}\text { Pre-HTN } \\
\% \\
(95 \% \mathrm{Cl})\end{array}$ & $\begin{array}{c}\mathrm{HTN} \\
\% \\
(95 \% \mathrm{Cl})\end{array}$ & $\begin{array}{l}\text { P-value } \\
\text { (trend) }\end{array}$ & $\begin{array}{c}\text { Normal BP } \\
\% \\
(95 \% \mathrm{Cl})\end{array}$ & $\begin{array}{c}\text { Pre-HTN } \\
\% \\
(95 \% \mathrm{Cl})\end{array}$ & $\begin{array}{c}\text { HTN } \\
\% \\
(95 \% \mathrm{Cl})\end{array}$ & $\begin{array}{l}\text { P-value } \\
\text { (trend) }\end{array}$ \\
\hline $\begin{array}{r}\text { No Additional } \\
\text { Risk Factor }\end{array}$ & $\begin{array}{c}54.1 \\
(47.9-60.3)\end{array}$ & $\begin{array}{c}45.6 \\
(37.1-54.1)\end{array}$ & $\begin{array}{c}19.6 \\
(10.5-28.7)\end{array}$ & $<0.001$ & $\begin{array}{c}48.4 \\
(43.9-52.8)\end{array}$ & $\begin{array}{c}22.6 \\
(16.2-29.2)\end{array}$ & $\begin{array}{c}6.7 \\
(3.6-9.7)\end{array}$ & $<0.001$ \\
\hline $\begin{array}{l}\text { I Additional } \\
\text { Risk Factor }\end{array}$ & $\begin{array}{c}33.1 \\
(26.5-39.6)\end{array}$ & $\begin{array}{c}28.0 \\
(21.9-34.1)\end{array}$ & $\begin{array}{c}29.1 \\
(20.5-37.7)\end{array}$ & 0.225 & $\begin{array}{c}33.6 \\
(29.3-37.9)\end{array}$ & $\begin{array}{c}40.9 \\
(35.3-46.5)\end{array}$ & $\begin{array}{c}26.1 \\
(20.6-31.5)\end{array}$ & $<0.001$ \\
\hline $\begin{array}{l}2 \text { Additional } \\
\text { Risk Factors }\end{array}$ & $\begin{array}{c}11.0 \\
(6.8-15.2)\end{array}$ & $\begin{array}{c}19.6 \\
(13.6-25.5)\end{array}$ & $\begin{array}{c}30.4 \\
(23.8-37.1)\end{array}$ & $<0.001$ & $\begin{array}{c}13.8 \\
(10.9-16.7)\end{array}$ & $\begin{array}{c}25.8 \\
(20.5-31.2)\end{array}$ & $\begin{array}{c}32.9 \\
(27.1-38.7)\end{array}$ & $<0.001$ \\
\hline $\begin{array}{r}\geq 3 \text { Additional } \\
\text { Risk Factors }\end{array}$ & $\begin{array}{c}1.8 \\
(0.4-3.2)\end{array}$ & $\begin{array}{c}6.8 \\
(3.5-10.2)\end{array}$ & $\begin{array}{c}20.9 \\
(15.0-26.7)\end{array}$ & $<0.001$ & $\begin{array}{c}4.2 \\
(2.4-6.1)\end{array}$ & $\begin{array}{c}10.6 \\
(7.6-13.5)\end{array}$ & $\begin{array}{c}34.3 \\
(28.8-39.8)\end{array}$ & $<0.001$ \\
\hline
\end{tabular}

I Currently smokes cigarettes regardless of quantity per day

2 Risk factors include diabetes mellitus, hypercholesterolemia, central obesity, cigarette smoking and age $>45$ years

while for two risk factors, the odds ratio was $2.3(1.3-3.8)$ and for one risk factor, the odds ratio was $2.3(1.4-4.0)$.

\section{Discussion}

The results of this study indicate that prehypertension affects almost one third of the Jamaican population. In this study the prevalence was higher in males compared to females in all age categories up to age 64 years and was similar in men and women in the oldest age category. Prehypertension was associated with several other risk factors for cardiovascular disease with significantly higher prevalence of overweight, obesity, increased waist circumfer- ence, hypercholesterolemia and diabetes mellitus when compared to persons with normal blood pressure. In addition, persons with prehypertension were more likely to have multiple additional CVD risk factors when compared to those with normal blood pressure.

The findings in our study are generally consistent with other studies in the published literature. Prevalence estimates reported range from $31 \%$ in the United States, $31.6 \%$ in Korea, 34\% in Taiwan, $40 \%$ in the Ashanti region of Ghana, to $47 \%$ in Liaoning Province in China and $48.9 \%$ among the military in Israel $[15-19,26]$. Except 
Table 4: Age specific odds ratios (with $95 \% \mathrm{Cl}$ in brackets) from multivariate logistic regression models for cardiovascular disease risk factors among prehypertensive persons compared to normotensive persons in the Jamaica Lifestyle Survey.

\begin{tabular}{|c|c|c|c|c|c|c|}
\hline \multirow[b]{2}{*}{ Risk Factor } & \multicolumn{6}{|c|}{ Age Group (years) } \\
\hline & $15-24$ & $25-34$ & $35-44$ & $45-54$ & $55-64$ & 65 \& older \\
\hline Obese $^{+}$ & $3.2(1.7-5.9)$ & $1.7(1.01-2.8)$ & $2.8(1.8-4.3)$ & $1.8(0.8-3.9)$ & I.I (0.5-2.5) & $0.9(0.2-3.5)$ \\
\hline Overweight $^{+}$ & $2.8(1.6-4.7)$ & $2.2(1.3-3.6)$ & $1.4(0.9-2.3)$ & $1.3(0.6-2.8)$ & $1.0(0.4-2.6)$ & $1.1(0.3-3.5)$ \\
\hline High cholesterol ${ }^{++}$ & $1.5(0.5-4.4)$ & $2.0(1.1-3.7)$ & $1.9(1.1-3.4)$ & $2.1(0.8-5.2)$ & $0.5(0.2-1.3)$ & $0.8(0.3-1.9)$ \\
\hline Diabetes $^{++}$ & \multicolumn{2}{|c|}{$0.7(0.2-2.7)^{+++}$} & $0.7(0.2-2.7)$ & $1.8(0.7-5.0)$ & $2.4(0.8-7.9)$ & $4.1(0.8-19.8)$ \\
\hline Increased Waist circumference ${ }^{+}$ & $3.1(1.6-5.9)$ & $2.0(1.1-3.3)$ & $1.4(0.9-2.2)$ & $1.6(0.8-3.3)$ & $1.6(0.5-4.7)$ & $1.6(0.4-5.7)$ \\
\hline Increased+ Waist/Hip ratio & $1.9(1.1-3.2)$ & $1.3(0.9-2.0)$ & $1.03(0.6-1.8)$ & $3.1(1.3-7.3)$ & $1.01(0.5-2.2)$ & $0.8(0.3-2.8)$ \\
\hline
\end{tabular}

+ Odds ratios adjusted for sex, diabetes and high cholesterol status

++ Odds ratios adjusted for sex and overweight status

${ }^{+++}$Odds ratios for age range 15-34 since there were no diabetes cases in the 15-24 year-olds.

for the $48.9 \%$ in Israel and the $47 \%$ from Liaoning Province in China these figures are generally similar to our estimates for Jamaica. The prevalence of prehypertension is therefore high in both developed and developing countries and in eastern and western populations. This supports the view that the rates of chronic noncommunicable diseases, in particular cardiovascular diseases, in developing countries are rapidly approaching the rates in developed countries and that their prevention requires urgent attention [27].

The association of prehypertension with multiple risk factors for cardiovascular disease has also been described in the American population where the odds of hypercholesterolemia, diabetes mellitus and overweight/obesity was found to be greater among persons with prehypertension compared to persons who were normotensive [10]. In Korea, persons with prehypertension were more likely to have the metabolic syndrome than persons who had normal blood pressure [15]. In addition the study from Israel found that both men and women with prehypertension were more likely to have hyperglycemia, dyslipidaemia, obesity, the metabolic syndrome and a $>15 \%$ ten year risk of CVD when compared to persons with normal blood pressure [16]. This clustering of cardiovascular disease risk factors among persons with prehypertension suggest that persons found to have prehypertension should be screened for other cardiovascular disease risk factors, regardless of age.

The higher prevalence of prehypertension among men (particularly younger men) compared to women is noteworthy. This finding of higher blood pressures among younger men compared to women has been previously reported in the Caribbean [28]. Overall, the high prevalence of prehypertension in the younger age groups suggest that although the absolute risk of CVD attributable to prehypertension may be low, the population attributable risk may be relatively high and therefore will have important public health implications.

Based on data from The Statistical Institute of Jamaica [29] the thirty percent prevalence of prehypertension represents approximately seven hundred and eighty thousand persons in Jamaica in this age range. Prior to the publication of JNC 7 these persons would have been considered to have "normal" blood pressure and may not have been recognized as potential candidates for cardiovascular intervention or risk reduction. We now know however, that persons with prehypertension are at increased risk of cardiovascular events including progression to hypertension. The evidence that these persons are at risk is now quite convincing and some studies have begun to evaluate the role of pharmacological intervention [30]. The need for intervention, whether lifestyle or pharmacological is supported by the findings of Russell et al. who estimated that among adults 25-74 years old in the United States, prehypertension alone accounted for $3.4 \%$ of hospitalizations, $6.5 \%$ of nursing home admissions and $9.1 \%$ of deaths [31]. These data suggest that prehypertension should probably be included in the various instruments for estimating cardiovascular risk among persons in the lower risk groups.

The public health implication of this increased burden of at-risk people in our population is worthy of serious evaluation. It has been estimated that a $5 \mathrm{mmHg}$ reduction in systolic blood pressure in the population will produce a $14 \%$ reduction in the risk of stroke and a $9 \%$ reduction in the risk of coronary heart disease [9]. If we apply a population approach to disease prevention we could therefore expect that a small reduction in mean population blood pressure will result in relatively large reductions in overall CVD risk. This can be achieved through either lifestyle or pharmacological intervention. It is unlikely that developing countries can afford pharmacological intervention [30] and lifestyle intervention $[9,32,33]$ may be difficult 
to implement and maintain. Any intervention strategy will therefore require a multi-level, multi-sectorial approach [34-36].

The cross-sectional design of our study prohibits any causal inference from the identified associations as a timesequence relationship cannot be determined. The study was population based and the sample was selected to be representative of the general Jamaican population. Where particular segments were not adequately represented weights were added to correct this prior to statistical analysis. One other possible limitation of this study is that there were missing data for some variables used in the analysis. The proportion of missing variables was however relatively small ranging from $3-8 \%$. In addition there were no significant differences in the mean values of demographic and available CVD characteristics, except for age, for those with any missing data compared to those with no missing data. We are therefore satisfied that the estimates presented reflect the situation in the general Jamaican population. Given the similarities between the Jamaican population and other countries of the English speaking Caribbean, it is likely that these findings are applicable to the other countries of the Caribbean region.

\section{Conclusion}

Prehypertension is highly prevalent in Jamaica and clusters with other cardiovascular disease risk factors. Health care providers and health planners should be made aware of the large numbers of persons at increased risk for cardiovascular disease and steps should be taken to identify and treat modifiable risk factors in such persons. At the very least a proper diet and regular exercise should be recommended. Further studies are needed to determine the rate of cardiovascular events in the prehypertensive population and the impact of various interventions on the rates of these cardiovascular events.

\section{Competing interests}

The authors declare that they have no competing interests.

\section{Authors' contributions}

TSF wrote the initial and revised manuscript and assisted with statistical analysis and interpretation of data; NOMY contributed to the design and conduct of original survey, performed statistical analyses and critically reviewed manuscript; MKT-R critically reviewed manuscript and assisted with statistical analyses and interpretation of data; MBLW critically reviewed manuscript and assisted with interpretation of data; EMW contributed to the design and conduct of original survey and critically reviewed manuscript; DEA contributed to the design and conduct of original survey and critically reviewed manuscript; RJW conceived, designed and managed the original survey; contributed to the interpretation of data and critically reviewed the manuscript and is the guarantor for the manuscript.

\section{Acknowledgements}

The authors are grateful to the Inter-American Development Bank and the Ministry of Health, Jamaica for funding the project.

The authors wish to acknowledge the contribution of the study coordinator Mrs. Jasneth Mullings, the supervisors, interviewers and participants as well as the Regional Health Authorities. We also acknowledge the support of the Ministry of Health and the University of the West Indies which contributed to the successful execution of the project.

TSF, NOMY, MKT-R, MBLW and RJW were supported by the University of the West Indies. EMW and DEA were supported by the Ministry of Health, Jamaica.

The funding agencies had no role in the design, conduct, analysis of the study or in the drafting and revision of the manuscript and the decision to submit for publication.

\section{References}

I. MacMahon S, Peto R, Cutler J, Collins R, Sorlie P, Neaton J, Abbott R, Godwin J, Dyer A, Stamler J: Blood pressure, stroke, and coronary heart disease. Part I, Prolonged differences in blood pressure: prospective observational studies corrected for the regression dilution bias. Lancet 1990, 335:765-774.

2. Lewington S, Clarke R, Qizilbash N, Peto R, Collins R: Age-specific relevance of usual blood pressure to vascular mortality: a meta-analysis of individual data for one million adults in 61 prospective studies. Lancet 2002, 360:1903-1913.

3. Vasan RS, Larson MG, Leip EP, Kannel WB, Levy D: Assessment of frequency of progression to hypertension in non-hypertensive participants in the Framingham Heart Study: a cohort study. Lancet 200I, 358: I682-I686.

4. Vasan RS, Larson MG, Leip EP, Evans JC, O'Donnell CJ, Kannel WB, Levy D: Impact of high-normal blood pressure on the risk of cardiovascular disease. N Engl J Med 200 I, 345: I 29|-I297.

5. Knight EL, Kramer HM, Curhan GC: High-normal blood pressure and microalbuminuria. Am J Kidney Dis 2003, 41:588-595.

6. Lemne C, Jogestrand T, de Faire U: Carotid intima-media thickness and plaque in borderline hypertension. Stroke 1995, 26(I):34-39.

7. Melina D, Colivicchi F, Guerrera G, Melina G, Frustaci A, Caldarulo $M$, Guerrera C: Prevalence of left ventricular hypertrophy and cardiac arrhythmias in borderline hypertension. Am J Hypertens 1992, 5(8):570-573.

8. Toikka JO, Laine H, Ahotupa M, Haapanen A, Viikari JS, Hartiala JJ, Raitakari OT: Increased arterial intima-media thickness and in vivo LDL oxidation in young men with borderline hypertension. Hypertension 2000, 36(6):929-933.

9. Chobanian AV, Bakris GL, Black HR, Cushman WC, Green LA, Izzo JL Jr., Jones DW, Materson BJ, Oparil S, Wright JT Jr., Roccella EJ: The Seventh Report of the Joint National Committee on Prevention, Detection, Evaluation, and Treatment of High Blood Pressure: the JNC 7 report. JAMA 2003, 289:2560-2572.

10. Greenlund KJ, Croft JB, Mensah GA: Prevalence of heart disease and stroke risk factors in persons with prehypertension in the United States, 1999-2000. Arch Intern Med 2004, 164:2||3-2|18.

II. Chrysohoou C, Pitsavos C, Panagiotakos DB, Skoumas J, Stefanadis C: Association between prehypertension status and inflammatory markers related to atherosclerotic disease: The ATTICA Study. Am J Hypertens 2004, I 7:568-573.

12. King DE, Egan BM, Mainous AG III, Geesey ME: Elevation of C reactive protein in people with prehypertension. J Clin Hypertens (Greenwich) 2004, 6:562-568.

13. Lawrence Wright MB, Devereux RB, Roman MJ, Chinali M, Best LG, Galloway J, et al:: Association of Prehypertension by Joint National Committee 7 Criteria with Left Ventricular Struc- 
ture and Function: The Strong Heart Study. J Am Coll Cardiol 2004, 43(5 Suppl A):5I3A.

14. Washio M, Tokunaga S, Yoshimasu K, Kodama H, Liu Y, Sasazuki S, Tanaka K, Kono S, Mohri M, Takeshita A, Arakawa K, Ideishi M, Nii T, Shirai K, Arai H, Doi Y, Kawano T, Nakagaki O, Takada K, Hiyamuta $\mathrm{K}$, Koyanagi $\mathrm{S}$ : Role of prehypertension in the development of coronary atherosclerosis in Japan. J Epidemiol 2004, 1 4:57-62.

15. Choi KM, Park HS, Han JH, Lee JS, Lee J, Ryu OH, Lee KW, Cho KH, Yoon D, Baik SH, Choi DS, Kim SM: Prevalence of prehypertension and hypertension in a Korean population: Korean National Health and Nutrition Survey 200 I. J Hypertens 2006 , 24:15|5-|52|.

16. Grotto I, Grossman E, Huerta M, Sharabi Y: Prevalence of prehypertension and associated cardiovascular risk profiles among young Israeli adults. Hypertension 2006, 48:254-259.

17. Tsai PS, Ke TL, Huang CJ, Tsai JC, Chen PL, Wang SY, Shyu YK: Prevalence and determinants of prehypertension status in the Taiwanese general population. J Hypertens 2005, 23: I355-1 360.

18. Wang $Y$, Wang Q]: The prevalence of prehypertension and hypertension among US adults according to the new joint national committee guidelines: new challenges of the old problem. Arch Intern Med 2004, 164:2 I 26-2I34.

19. Sun Z, Zheng L, Wei Y, Li J, Zhang X, Zhang X, Liu S, Xu C, Li , Zhao F, Hu D, Sun Y: Prevalence and risk factors of the rural adult people prehypertension status in Liaoning Province of China. Circ J 2007, 7 I:550-553.

20. Wilks RJ, Younger N, Ashley DE, Ward E, Mullings J, Bennett F, Forrester TE: Obesity, hypertension, and diabetes mellitus in the Jamaican population. West Indian Med J 2003, 52 (Suppl. 3):4I-42.

21. Wilks R, Younger N, Mullings J, Zohoori N, Figueroa P, Tulloch-Reid M, Ferguson T, Walters C, Bennett F, Forrester T, Ward E, Ashley D: Factors affecting study efficiency and item non-response in health surveys in developing countries: the Jamaica national healthy lifestyle survey. BMC Med Res Methodol 2007, 7:13.

22. Definition, Diagnosis and Classification of Diabetes Mellitus and its Complications. Report of a WHO Consultation. 1999. WHO/NCD/NCS/99.2:.

23. Physical status: the use and interpretation of anthropometry. Report of a WHO Expert Committee. World Health Organ Tech Rep Ser 1995, 854: I-452.

24. Lean ME, Han TS, Morrison CE: Waist circumference as a measure for indicating need for weight management. BM] 1995 3 I I(6998): $158-161$.

25. Stata Statistical Software. College Station, Texas, Stata Corporation; 2007.

26. Agyemang C, Owusu-Dabo E: Prehypertension in the Ashanti region of Ghana, West Africa: An opportunity for early prevention of clinical hypertension. Public Health 2008, 122:19-24.

27. Leeder S, Raymond S, Greenberg H, Liu H, Esson K: A Race Against Time. The Challenge of Cardiovascular Disease in Developing Countries. The Centre for Global health and Economic Development; 2004.

28. Hagley KE: Chronic non-communicable diseases and their impact on Caribbean women. West Indian Med J 1990, 39:4-II.

29. Jamaica SI: Population Census Fact Sheet 200I. 2004 [http:// www.statinja.com/census.html].

30. Julius S, Nesbitt SD, Egan BM, Weber MA, Michelson EL, Kaciroti N, Black HR, Grimm RH Jr., Messerli FH, Oparil S, Schork MA: Feasibility of treating prehypertension with an angiotensin-receptor blocker. N Engl J Med 2006, 354:1685-1697.

31. Russell LB, Valiyeva E, Carson JL: Effects of prehypertension on admissions and deaths: a simulation. Arch Intern Med 2004, 164:2119-2124.

32. Puska P: Nutrition and mortality: the Finnish experience. Acta Cardiol 2000, 55:2 13-220.

33. Whelton PK, He J, Appel LJ, Cutler JA, Havas S, Kotchen TA, Roccella EJ, Stout R, Vallbona C, Winston MC, Karimbakas J: Primary prevention of hypertension: clinical and public health advisory from The National High Blood Pressure Education Program. JAMA 2002, 288: I882-I888.

34. Reddy KS, Yusuf S: Emerging epidemic of cardiovascular disease in developing countries. Circulation 1998, 97:596-60I.

35. Barcelo A: Cardiovascular diseases in Latin America and the Caribbean. Lancet 2006, 368:625-626.
36. Reddy KS: Cardiovascular diseases in the developing countries: dimensions, determinants, dynamics and directions for public health action. Public Health Nutr 2002, 5:23I-237.

\section{Pre-publication history}

The pre-publication history for this paper can be accessed here:

http://www.biomedcentral.com/1471-2261/8/20/prepub
Publish with Bio Med Central and every scientist can read your work free of charge

"BioMed Central will be the most significant development for disseminating the results of biomedical research in our lifetime. "

Sir Paul Nurse, Cancer Research UK

Your research papers will be:

- available free of charge to the entire biomedical community

- peer reviewed and published immediately upon acceptance

- cited in PubMed and archived on PubMed Central

- yours - you keep the copyright 